\title{
A Method to Determine Cutting Force Coefficients in Turning Using Mechanistic Approach
}

\author{
T. C. Bera, H. Manikandan, A. Bansal, and D. Nema
}

\begin{abstract}
During performing turning operation, cutting force plays a significant role in metal cutting process affecting tool-workpiece deflection, machine tool vibration and eventually part quality. The present research work aims to develop a mechanistic cutting force model that will be used in development of tool-workpiece flexible system of thin-wall machining. It also concentrates to study the mechanistic constants used in the force model in case of turning operation. The proposed model can be used for the reliable and accurate estimation of the cutting forces establishing relationship of various force components (cutting force and feed force) with uncut chip thickness. The accurate estimation of cutting force is required to improve thin-walled part accuracy by controlling the tool-workpiece deflection induced surface errors and tool-workpiece vibration.
\end{abstract}

Keywords-Turning, cutting forces, cutting constants, uncut chip thickness.

\section{INTRODUCTION}

Turning is one of the most common and versatile manufacturing processes used for various industries such as automobile, aerospace, biomedical sectors etc. During performing turning operation, cutting force plays a major role in metal cutting process affecting tool-workpiece deflection, machine tool vibration and eventually part quality. Therefore, accurate estimation of cutting forces in turning becomes an important factor to process characterization, process optimization and above all to enhance machining performance. Moreover, there are many situations like machining of thin-walled components where reliable prediction of cutting forces is essential for workpiece dimensional as well as geometrical accuracy. The precise and reliable estimation of cutting force largely depends on cutting force coefficients, the determination of which is the foundation of cutting force model. The proper identification and determination of cutting force coefficients have great influence in modeling of cutting forces [1].

There are several research work have been done regarding modeling of cutting forces in turning. They can be categorized broadly into three different groups. The first one is analytical approach which facilitates to establish mathematical relationship between cutting forces and various mechanical aspects such as cutting tool geometry, friction,

Manuscript received December 17, 2016; revised March 11, 2017. This work was supported in part financially by Science and Engineering Research Board (SERB), Department of Science and Technology (DST), Government of India. (Project No: SB/FTP/ETA-03/2013).

The authors are with the Department of Mechanical Engineering, Birla Institute of Technology and Science Pilani, Rajasthan-333031, India (email: tcbera@pilani.bits-pilani.ac.in, manikandan.h@pilani.bits-pilani.ac.in, ankitbansal1993@gmail.com,devashish.nema@gmail.com). process parameters, mechanical behaviour of workpiece materials etc. Earlier Merchant, Shaffer and Oxley attempted on developing analytical model for orthogonal and oblique cutting of metals [2]-[4]. Recently, Jawahir et al. [5] concentrates on understanding of the basic characteristics of machining processes using universal slip-line model for restricted contact tools. This kind of analytical models along with the theory of slip-lines is able to predict directly the cutting forces, friction, stresses, strains, strain rates and temperatures in the local cutting zone. Another one analytical force model is developed by Elbestawi et al. [6] for oblique cutting of metals based on chip formation and chip morphology. Kishawy et al. [7] proposed one more analytical force model for metal matrix composites by considering the effect of particle sizes on machining forces. More recently, Altintas et al. [8] studied on a unified mathematical model for prediction of chatter stability for multiple machining operations such as turning, boring, drilling and milling with defined cutting edges. Although analytical models are more generic in nature, predicted forces are not very accurate in oblique cutting operation due to determination of cutting constants by orthogonal cutting parameters that limits the use of analytical models in various cutting processes.

The second one is numerical approach which deals with fundamental mechanics and physics of metal cutting concentrating tool tip contact zone and interaction of tool-workpiece pair [9], [10]. Recently, Altintas et al. [11] developed a simulation model of metal cutting process in a more generalized way using ALE (Arbitrary Lagrangian Eulerian) method. Later on Schermann et al. [12] studied on metal cutting process including coupling process and dynamic behaviour of the machine tool using finite element method (FEM). More recently, Ozel et al. [13] concentrated on 3D machining of Inconel 718 incorporating large elastic-plastic deformation, high temperature change and high strain rates. Although this type of model has lot of advantages, but they are limited to simple orthogonal and oblique cutting. Computational cost is also very high in case of numerical models.

The third one is mechanistic approach which is semi-analytical in nature dealing with a series of experiments between machining parameters and cutting forces. This approach takes into account the geometrical characteristic of metal cutting process and empirical cutting constants obtained from experiments for a specific tool-workpiece pair. Although mechanistic model is very specific for a tool-workpiece pair, the calibration time of cutting constant is very short and it incorporates complex tool geometry into metal cutting process. It has enough capability to predict accurate cutting forces for a wide range of cutting conditions subject to a tool-workpiece pair. Therefore, an attempt has 
been made in the present work to identify and determine the specific cutting constants for estimating accurate cutting forces for turning of Al 6351 T6 material.

Henceforth, this paper is organized as follows: In Section II, the process geometry model of turning is described. The Section III deals with the proposed mechanistic approach in turning. It is described to identify and determine the cutting constants for cutting force model of turning. Using the cutting constant, cutting force model is developed and described in detail. Section IV deals with experimental setup and machining conditions chosen for the present research work. Section V illustrates the results and discussions of the proposed model. Finally, conclusion based on the present study has been summarized in Section VI.

\section{PROCESS GEOMETRY OF TURNING}

Turning is a continuous metal cutting process in which a non-rotary cutting tool moves linearly parallel to job axis while workpiece rotates about its own axis. Generally, this operation is carried out on lathe machine tool. The machined surface of workpiece in turning depends on three important factors namely tool geometry, workpiece geometry and relative motion and interaction between tool and workpiece. The rotational motion of job, linear motion of cutting tool and their complex interactions define the final shape of the machined components. It is well known that to perform turning operation basic input process parameters are cutting speed, nominal feed rate and nominal depth of cut. Final shape of machined surface will be produced based on relative motion and interaction of these input process parameters and geometry of complex cutting tool. Therefore, it is essential to study process geometry of turning and process geometry variables such as actual feed per revolution, actual depth of cut and peripheral cutting speed of workpiece.

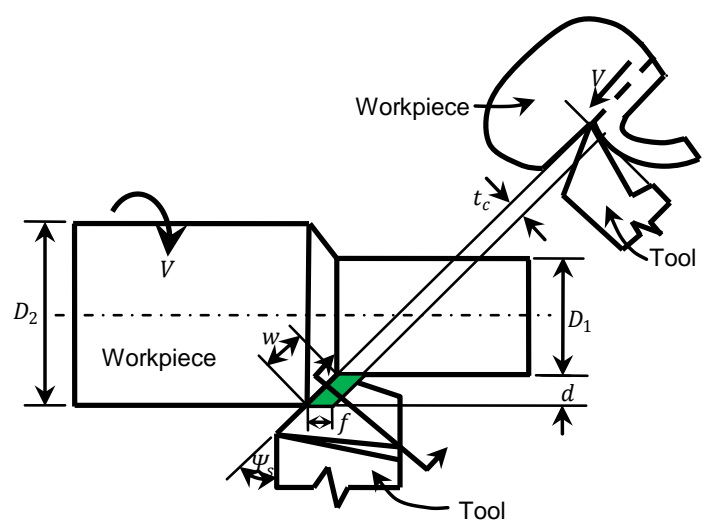

Fig. 1. Process geometry of turning.

The Fig. 1 shows a schematic representation of turning process describing various process geometry variables such as actual feed per revolution, actual depth of cut and peripheral cutting speed of workpiece.

The process geometry variables are actual or true feed per revolution, actual or true depth of cut and peripheral cutting speed. These variables are determined based on the cutting parameters used in machining process such as spindle rpm, nominal feed rate and nominal depth of cut. Cutting speed can be calculated using Eq. (1).

$$
V=\pi D_{1} N
$$

where $V$ is cutting speed in $\mathrm{mm} / \mathrm{min}, D_{1}$ is final diameter of the workpiece, $N$ is spindle rpm. The nominal feed per revolution ( $f$ ) can be computed using Eq. (2).

$$
f=\frac{f_{r}}{N}
$$

where $f_{r}$ is nominal feed rate in $\mathrm{mm} / \mathrm{min}$. Nominal depth of cut $(d)$ can be determined using Eq. (3).

$$
d=\frac{\left(D_{2}-D_{1}\right)}{2}
$$

where $D_{2}$ and $D_{1}$ are initial and final diameter of the workpiece in $\mathrm{mm}$ respectively. From Fig. 2, it is seen that both nominal feed and nominal depth of cut are dependent on side cutting edge angle $\left(\Psi_{S}\right)$ that can be known from the cutting tool nomenclature. Therefore, actual uncut chip thickness $\left(t_{c}\right)$ can be calculated from the Eq. (4) as shown below.

$$
t_{c}=f \cos \left(\psi_{s}\right)
$$

In similar manner, actual depth of cut $(w)$ can be determined using Eq. (5).

$$
w=\frac{d}{\cos \left(\psi_{s}\right)}
$$

Therefore, from the Fig. 2, it can be seen that effective cutting area $\left(A_{c}\right)$ is the product of actual uncut chip thickness $\left(t_{c}\right)$ and actual depth of cut $(w)$. From the Fig. 2, it can also be seen that the effective cutting area is also product of nominal feed per revolution and nominal depth of cut and it can easily be calculated using Eq. (6).

$$
A_{c}=t_{c} \cdot w=f_{d}
$$

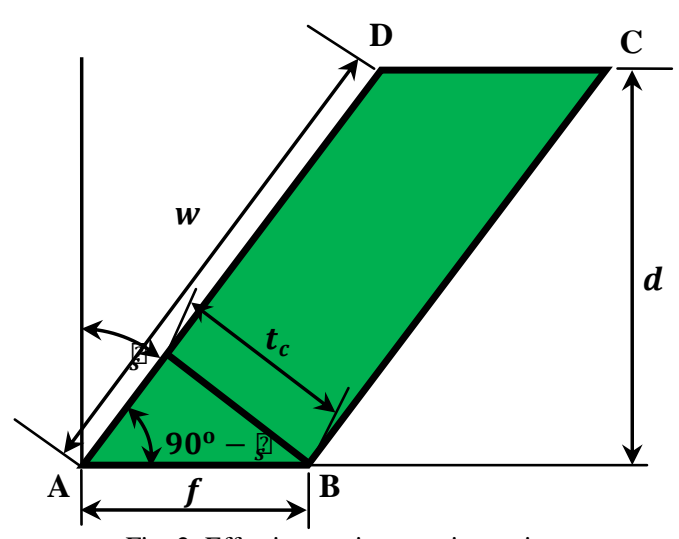

Fig. 2. Effective cutting area in turning.

\section{MEChANISTIC APPROACH IN TURNING}

The mechanistic approach can be defined as a combination of both analytical as well as experimental approaches. In mechanistic approach, instantaneous uncut chip thickness is determined analytically from the process geometry model considering the interactions of tool and workpiece. The cutting coefficients or cutting constants are determined 
experimentally for various values of uncut chip thickness keeping depth of cut same. Later on, empirical relationships are established among geometrical parameters obtained from the process geometry of turning.

Mechanistic model considers that cutting force is proportional to actual effective cutting area. The constant of proportionality is known as cutting force coefficient or cutting constant or cutting pressure constant. The cutting force constant depends on several factors such as tool and workpiece material, tool geometry. Due to these significant factors, cutting force constant is difficult to quantify in many cases. Therefore, a reliable method is required to identify and determine the cutting pressure constant. A direct calibration method is used to determine the same. A series of machining tests are conducted to establish the cutting force coefficients over a range of cutting conditions. Mechanistic model considers that cutting force is proportional to the chip cross-sectional area or effective cutting area. The constant of proportionality is known as cutting force coefficient or cutting constant or cutting pressure constant. The cutting force constant depends on several factors such as tool and workpiece material, tool geometry. Due to these significant factors, cutting constant is difficult to quantify in many cases. Therefore, a reliable method is required to identify and determine the cutting constant. A direct calibration method is used to determine the same. A series of machining tests are conducted to establish the cutting force coefficients over a range of cutting conditions [14]. The cutting constant is directly related to the mechanics of metal cutting and tool-workpiece interaction which is shown in the Fig. 1. To obtain the magnitude of cutting force, the cutting constant is multiplied with effective area of cutting. This effective cutting area depends on actual radial depth of cut and actual uncut chip thickness. Cutting force component and feed force component can be obtained from the following equations.

$$
\begin{aligned}
& F_{C}=K_{c} \cdot A_{c} \\
& F_{F}=K_{f} \cdot A_{c}
\end{aligned}
$$

where $F_{C}$ is cutting force component and $F_{F}$ is feed force component respectively. $K_{c}$ and $K_{f}$ are the cutting constants for cutting force and feed force components. These cutting constants are also known as cutting force coefficients or cutting pressure constants. Many researchers [1]-[3] are expressed the mechanistic constants as non-linear function of uncut chip thickness in more general form given below:

$$
\begin{gathered}
K_{c}=K_{C}\left(t_{c}\right)^{p} \\
K_{f}=K_{F}\left(t_{c}\right)^{q}
\end{gathered}
$$

where $K_{C}$ and $K_{F}$ are specific constant for cutting force and feed force components. $p$ and $q$ are constants used in power function.

\section{EXPERIMENTAL SETUP}

All machining experiments are carried out on a conventional lathe equipped with piezoelectric dynamometer (Kistler) based cutting force measurement setup as shown in Fig. 3.

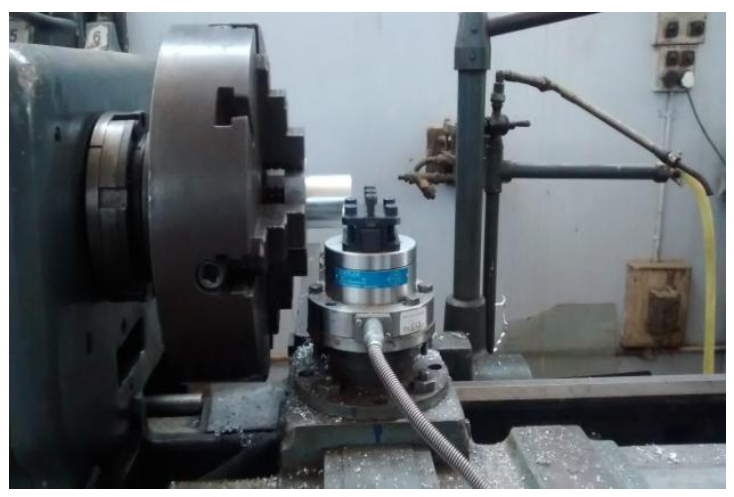

Fig. 3. Experimental setup.

The workpiece material and cutting tool selected during machining experiments are Aluminum 6351-T6 and carbide insert (TNMG $160408 \mathrm{CQ}$ ) respectively. The pre-machined hollow cylindrical workpiece is produced from rectangular components using roughing and semi-finishing operation prior to final cut. The one end of cylindrical workpiece is attached to the square base mounted on four jaw chuck and other end is free as shown in Fig. 4.

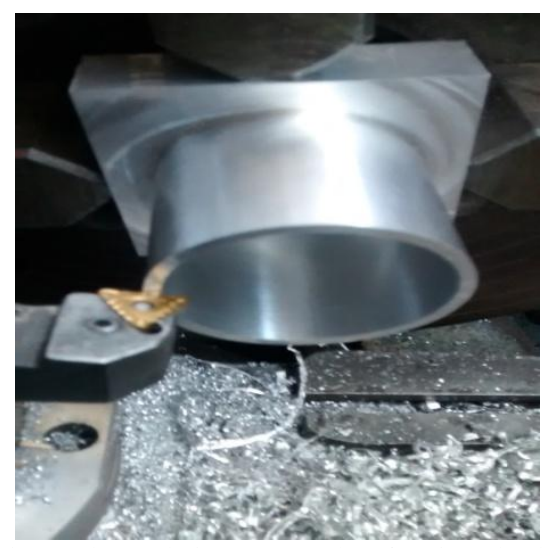

Fig. 4. The workpiece mounted on four jaw chuck.

The length of cylindrical workpiece is $75 \mathrm{~mm}$ from the to surface of the square base having dimensions of $75 \mathrm{~mm} \times 75$ $\mathrm{mm} \times 25 \mathrm{~mm}$. The outer and inner diameter of the workpiece is $55 \mathrm{~mm}$ and $49 \mathrm{~mm}$ respectively and thickness is $3 \mathrm{~mm}$. Free orthogonal cutting is performed for each machining experiment for the duration of 20 seconds and cutting forces are measured by piezoelectric dynamometer and recorded the same using DAQ system. Later on, DYNOWARE software was used to process the recorded data to obtain average cutting force and feed force components. Other machining conditions are listed in the Table I.

TABLE I: CUTTING CONDITIONS

\begin{tabular}{|l|l|}
\hline Workpiece geometry & Hollow cylinder \\
\hline Outer diameter $(\mathrm{mm})$ & 55 \\
\hline Inner diameter $(\mathrm{mm})$ & 49 \\
\hline Wall thickness $(\mathrm{mm})$ & 3 \\
\hline Nominal depth of cut $(\mathrm{mm})$ & 3 \\
\hline Feed per revolution $(\mathrm{mm} / \mathrm{rev})$. & $0.04,0.08,0.12,0.16$ \\
\hline Feed rate $(\mathrm{mm} / \mathrm{min})$ & $6,15,30,51$ \\
\hline Spindle rpm & $147,190,247,320$ \\
\hline Cutting speed $(\mathrm{m} / \mathrm{min})$ & $25.39,32.83,42.68,55.29$ \\
\hline Cutting tool type & Carbide insert \\
\hline Cutting type & Orthogonal cutting without coolant \\
\hline
\end{tabular}

Each experiment is performed on the same experimental 
setup by varying feed rate keeping depth of cut and cutting speed constant. According to mechanistic approach, empirical relationships are established among geometrical parameters obtained from the process geometry of turning. Depending on the machining conditions, effective cutting area has been calculated based on actual uncut chip thickness and actual depth of cut. The magnitudes of cutting forces are collected from the recorded data obtained from DYNOWARE commercial package for the given machining condition. Later on, cutting constants are computed for given machining conditions for a specific tool-workpiece pair. The detailed discussions about cutting constants and their dependency on process geometry variables have been presented in the following section.

\section{RESULTS AND DISCUSSIONS}

This section analyzes the behavioral characteristics of cutting constants for given tool-workpiece pair and their dependency on uncut chip thickness. The values of cutting constants considered as dependent variables have been plotted against the uncut chip thickness as independent variable. The Fig. 5 represents the graph for cutting constant $\left(K_{c}\right)$ for cutting force component versus uncut chip thickness.

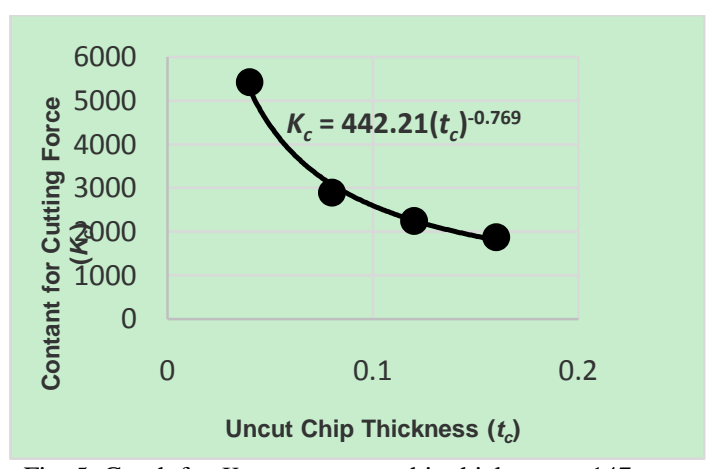

Fig. 5. Graph for $K_{c}$ versus uncut chip thickness at $147 \mathrm{rpm}$.

From the Fig. 5, it is clearly observed that the magnitude of the cutting constant $\left(K_{c}\right)$ decreases with increase of uncut chip thickness. As uncut chip thickness is function of feed rate, cutting constant $\left(K_{c}\right)$ is also dependent on feed rate. When feed per revolution increases the sheared uncut chip thickness increases because the metal resists the rupture more and requires larger efforts for chip removal. Hence, the cutting force component also increases as the feed rate increases.

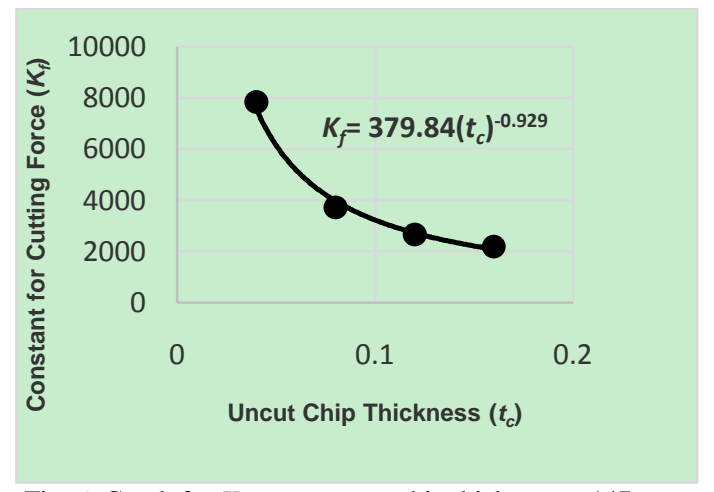

Fig. 6. Graph for $K_{f}$ versus uncut chip thickness at $147 \mathrm{rpm}$.

From the Fig. 6, it can clearly be examined that the nature of the graph for cutting constant of feed force component versus uncut chip thickness is almost same although its magnitude is different. The magnitude of the cutting constant $\left(K_{f}\right)$ decreases with increase of uncut chip thickness. It can be justified that uncut chip thickness is function of feed rate. Therefore, cutting constant $\left(K_{f}\right)$ is also dependent on feed rate. When feed rate is more the uncut chip thickness will be more because the metal resists the more rupture of shear zone which requires larger efforts to remove chip from the cutting zone. Hence, the feed force also increases because of larger effective cutting area. The calculated values of specific constants $\left(K_{C}, K_{F}\right)$ are given in the Table II.

TABLE II: THE VALUES OF SPECIFIC CONSTANTS
\begin{tabular}{|c|c|c|c|c|c|}
\hline SL No. & RPM & $K_{C}$ & $p$ & $K_{F}$ & $q$ \\
\hline 1 & 147 & 442.21 & -0.769 & 379.84 & -0.929 \\
\hline 2 & 190 & 389.65 & -0.777 & 377.34 & -0.879 \\
\hline 3 & 247 & 395.20 & -0.677 & 381.26 & -0.808 \\
\hline 4 & 320 & 366.74 & -0.650 & 355.73 & -0.773 \\
\hline
\end{tabular}

\section{CONCLUSIONS}

In the present study, mechanistic cutting constants are identified and determined for given pair of tool-workpiece combination. The relationship between cutting constants and uncut chip thickness is successfully established to develop cutting force model. A more generic relationship between mechanistic constant and uncut chip thickness has been established in non-linear form within an acceptable range of error for the specific range of cutting speeds. The accurate value of cutting constants are essential for precise and reliable estimation of cutting force. Later on, these cutting force values will be used to process control, process characterization and to enhance machining performance for machining of thin-walled components by developing tool-workpiece flexible system.

\section{REFERENCES}

[1] W. A. Kline, R. E. DeVor, and J. R. Lindberg, "The prediction of cutting forces in end milling with application to cornering cuts," International Journal of Machine Tool Design and Research, vol. 22, pp. 7-22, June 1982.

[2] E. Merchant, "Basic mechanics of the metal cutting process," ASME Trans. Journal of Applied Mechanics, vol. 11, pp. 168-175, Jan. 1944.

[3] L. H. Lee and B. W. Shaffer, "The theory of plasticity applied to a problem of machining," ASME Trans. Journal of Applied Mechanics, vol. 73, pp. 405-413, 1951 .

[4] W. B. Palmer and P. L. B. Oxley, "Mechanics of orthogonal machining," Proceedings of the Institute of Mechanical Engineers, vol. 173, pp. 623-654, 1959.

[5] N. Fang, I. S. Jawahir, and P. L. B. Oxley, "A universal slip-line model with non-unique solutions for machining with curled chip formation and a restricted contact tool," International Journal of Mechanical Sciences, vol. 43, pp. 557-580, 2001.

[6] C. E. Becze and M. A. Elbestawi, "A chip formation based analytic force model for oblique cutting," International Journal of Machine Tools and Manufacture, vol. 42, pp. 529-538, 2002.

[7] S. Sikder and H. A. Kishawy, "Analytical model for force prediction when machining metal matrix composite," International Journal of Mechanical Sciences, vol. 59, pp. 95-103, 2012.

[8] Y. Altintas and Z. M. Kilic, "Generalized dynamic model of metal cutting operations," CIRP Annals Manufacturing Technology, vol. 62, pp. 47-50, 2013.

[9] C. A. Van Luttervelt, T. H. C. Childs, I. S. Jawahir, F. Klocke, and P. K. Venuvinod, "Present situation and future trends in modeling of machining operations progress report of the CIRP working group 
modelling of machining operations," CIRP Annals, Manufacturing Technology, vol. 47, pp. 587-626, 1998.

[10] J. Mackerle, "Finite-element analysis and simulation of machining a bibliography (1976-1996)," Journal of Materials Processing Technology, vol. 86, pp. 17-44, 1999.

[11] M. R. Movahhedy, M. R. Gadala, and Y. Altintas, "Simulation of chip formation in orthogonal metal cutting process: An ALE Finite Element Approach, Machining Science and Technology, vol. 4, pp. 15-42, 2000

[12] T. Schermann, J. Marsolek, C. Schmidt, and J. Fleischer, "Aspects of the simulation of a cutting process with ABAQUS/Explicit, including the interaction between the cutting process and the dynamic behaviour of the machine tool," in Proc. he 9th CIRP International Workshop on Modeling of Machining Operations, Bled, Slovenia, 2006.

[13] T. Ozel, I. Llanos, J. Soriano, and P. J. Arrazola, "3D Finite element modelling of chip formation process for machining inconel 718: comparison of FE software predictions," Machining Science and Technology, vol. 15, pp. 21-46, 2011.

[14] W. J Endres, R. E. DeVor, and S. G. Kapoor "A dual-mechanism approach to the prediction of machining forces, Part 1: Model development," Transactions of the ASME Journal of Engineering for Industry, vol. 117, pp. 526-533, 1995.

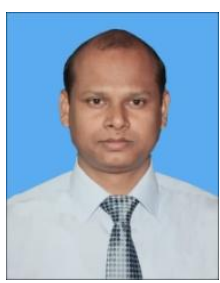

T. C. Bera is presently working as an assistan professor in the Department of Mechanical Engineering, Birla Institute of Technology and Science Pilani, Rajasthan, India. He was born on 12th November, 1980 at Jagannathpur in the district of Paschim Medinipur, West Bengal, India. He completed his Bachelor of Engineering (B.E) from Production Engineering, Jadavpur University (JU) ranking first class with honours in 2003. He did his Master of Engineering (M.E) from Mechanical Engineering, Bengal Engineering and Science University, Shibpur in 2005. After that, he joined in the Department of Mechanical Engineering, Indian Institute of Technology Delhi as a research scholar for pursing his PhD program. In 2010, he joined in the Department of Mechanical Engineering, BITS Pilani as lecturer. Mean while, he had been awarded PhD degree from IIT Delhi in 2011. He has been working as an assistant professor since 2011 in BITS Pilani. His area of interest in research is conventional and non-conventional machining and $\mathrm{CAD} / \mathrm{CAM} / \mathrm{CAE}$. His area of interest in teaching includes manufacturing science, $\mathrm{CAD} / \mathrm{CAM}$ and $\mathrm{CNC}$ technology.

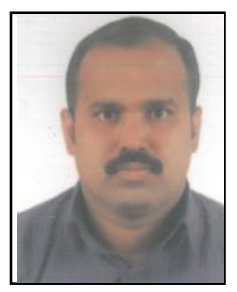

H. Manikandan is currently working as a Senior Research Fellow in the Department of Mechanical Engineering, Birla Institute of Technology and Science Pilani, Rajasthan, India. He was born on 27th May 1985 at Kottayam in the district of Kottayam, Kerala, India. He completed his Bachelor of Technology (B. Tech) in Production Engineering from University of Kerala, Thiruvananthapuram, Kerala in 2006. He did his Master of Engineering (M.E) in
Mechanical Engineering from Anna University, Chennai, Tamil Nadu in 2013. He worked as a Lecturer in Mechanical Engineering at University of Calicut, Kerala from 2009 to 2010 . He is also having one year teaching experience in the School of Engineering, Cochin University of Science and Technology (CUSAT), Kochi, Kerala (2010-2011). His area of interest in research is Machining, CAD/CAM. His area of interest in teaching includes Manufacturing Science, CAD/CAM and Safety Engineering.

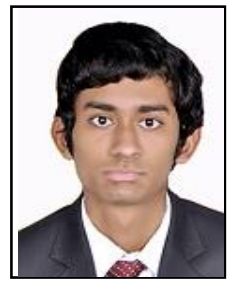

Devashish Nema is currently working as a summer intern in Tata Motors Limited, Pimpri plant, Pune, Maharashtra. He was born on 22nd June, 1993 in Sagar district of Madhya Pradesh. He is pursuing Bachelor of Engineering (B.E) in Manufacturing Engineering from the Department of Mechanical Engineering, Birla Institute of Technology and Science, Pilani. He is to graduate in June 2015. He has previously worked as an intern at Bharat Forge Limited, Mundhwa plant, Pune in 2013 and at MAN Trucks India Limited, Pithampur plant, Indore in 2014. His research interests are CAD/ CAM and sustainable manufacturing.

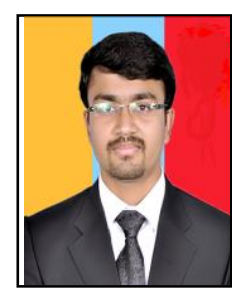

A. Bansal was born at Bikaner, in the Indian state of Rajasthan on 19th July, 1993 and is currently pursuing Bachelor of Engineering (Hons.) in Manufacturing Engineering from the Department of Mechanical Engineering, Birla Institute of Technology and Science Pilani, Rajasthan-333031, India. He is to graduate in May 2015. He joined Tata Motors' Nano plant in Ahmedabad, Gujrat as an Industrial Trainee in January 2015 and is working on improving product quality through incorporation of an intelligent defect capturing system. He has also worked at Toyota Kirloskar Motors and Bhushan Steels Limited as Summer Intern in both organizations during June \& July of 2014 and 2013 respectively. Mr. Bansal has been an active member of the American Society of Mechanical Engineers (ASME), regularly participating in competitions like Shell Eco Marathon - Asia, Philippines, Human Powered Vehicle Challenge, Delhi and conferences like Student Professional Development Conference - Asia Pacific 2014. His areas of research include internal combustion engines, $\mathrm{CAD} / \mathrm{CAM}$ and CNC technology. 